\title{
Delayed metamorphosis of a tropical reef fish (Acanthurus triostegus): a field experiment
}

\author{
Mark I. McCormick* \\ Department of Marine Biology, James Cook University, Queensland 4811, Australia
}

\begin{abstract}
Larval duration of a demersal fish is a product of its genotype, its larval environment and the capacity of the species to delay metamorphosis. Circumstantial evidence has led to the hypothesis that the lower age-limit for settlement is governed by the rate of larval development, while the upper age-limit is determined by the extent to which a delay of metamorphosis is possible. This study examined the capacity of a widely distributed reef fish, the manini Acanthurus triostegus, to extend its larval duration by delaying metamorphosis. Variation in larval duration was examined from 8 samples of manini collected in French Polynesia using crest nets over a 2 yr period. Variation in the overall age at colonisation determined from daily otolith increments was very low (CV $5.5 \%$ ) given the pan-Pacific distribution pattern of the species. A field experiment was conducted to determine whether manini could delay metamorphosis. To enable its interpretation, the metamorphosis of the species was characterised morphologically. Metamorphosis involved a loss of transparency, a shortening of fin spines and a migration of the mouth from a terminal to ventral position over a $5 \mathrm{~d}$ period. To experimentally examine the capacity of the species to delay metamorphosis manini were caught at night as they colonised a reef and placed in 1 of 2 treatments: benthic cages in the shallow backreef, or fine monofilament cages suspended between 3 and $6 \mathrm{~m}$ in a $50 \mathrm{~m}$ water column on the outer reef slope. Fish in benthic cages completed metamorphosis within $5 \mathrm{~d}$. In contrast, $24 \%$ of fish in pelagic cages ( 8 out of 34 fish) remained transparent (although some developed faint stripes) and retained the pelagic body shape. Fish that delayed metamorphosis still deposited a mark on their otoliths indistinguishable in structure from the settlement marks deposited on otoliths of their benthic-caged counterparts and reefcaught juveniles. This is the first experimental evidence that the settling stages of some demersal fish species can delay metamorphosis in the reef environment. As such it supports the conceptual model generally applied to the selective settlement of demersal fishes.
\end{abstract}

KEY WORDS: Coral reef fish - Metamorphosis Recruitment - Settlement - Larval duration - Delayed metamorphosis - Growth - Otolith - Field experiment

\section{INTRODUCTION}

The general framework in which ecologists examine the process of replenishment in demersal fishes involves late-stage larvae, which have dispersed from their natal location, reaching suitable settlement sites. A species-specific change in morphology and physiology, called metamorphosis, occurs at settlement during which fish lose many of the characteristics that enhance survival in the plankton while developing other features suited to their new benthic environment

\footnotetext{
-E-mail: mark.mccormick@jcu.edu.au
}

(e.g. Randall 1961, Norris 1963, Markle 1992, Keefe \& Able 1993, McCormick 1993, McCormick \& Shand 1993, Shand 1993, 1994, 1997). Failure of larvae to reach a suitable settlement site results in an increased probability of death by either metamorphosing to a form not suited to the pelagic environment, or growing beyond some optimal size set by physiology, resource use and predation. It has been suggested that some widely distributed families of fishes, such as the wrasses, surgeonfishes and flatfishes, have the capacity to delay metamorphosis, thereby increasing their probability in finding suitable settlement habitat (Randall 1961, Victor 1986, Evans \& Fernald 1990, Cowen 1991, Jenkins \& May 1994, McCormick 1994, Cowen \& 
Sponaugle 1997, Sponaugle \& Cowen 1997). Circumstantial evidence has led to the theory that there is a temporal window of opportunity for metamorphosis and settlement, with the lower bound governed by the rate of development, while the upper bound is determined by the extent to which a delay of metamorphosis is possible.

Variability in larval duration among individuals of a species has been shown experimentally to be a product of genotype (Chambers \& Leggett 1992) and environmental factors during the pre-competent period of the pelagic stage, such as food availability (McCormick \& Molony 1992) and water temperature (Keefe \& Able 1993, McCormick \& Molony 1995). To date, only circumstantial evidence supports the ability of some fish species to delay metamorphosis once competence has been reached. The most compelling evidence is the reduced otolith growth in the late-larval stages of fishes with extended larval durations (e.g. Victor 1986, Cowen 1991, Jenkins \& May 1994, Fowler \& Short 1996, Sponaugle \& Cowen 1997). The most often quoted example of delayed metamorphosis is for the Caribbean wrasse Thalassoma bifasciatum (Victor 1986), where less than $1 \%$ of fish collected were found to have extended larval durations. This and most other studies assume, rather than demonstrate, the ability of the fish to delay metamorphosis, under the assumption that fish above an arbitrarily defined larval duration have delayed metamorphosis (e.g. Victor 1986, Sponaugle \& Cowen 1994, Masterson et al. 1997). At present, there has been no test of a fish's ability to delay metamorphosis and settlement in the absence of a suitable settlement substratum. The paucity of evidence for demersal fishes contrasts with an extensive body of invertebrate literature, for which delays in settlement are well documented and experimentally examined (e.g. Richmond 1985, Lipcius et al. 1990, Pechenik 1990, Pechenik et al. 1993, Davis 1994, Harvey 1996, Stoner et al. 1996). The present study is the first to experimentally examine in the field the capacity of a fish species to delay metamorphosis.

A record of delayed metamorphosis may reside in aberrations in the daily increment structure laid down in a fish's calcareous structures. Almost all vertebrates examined form growth increments in the hard parts of the body and daily increments are particularly clear in the otoliths of fishes (Campana \& Neilson 1985). Marked changes in the morphology of these regular increments have been found to coincide with settlement (e.g. Victor 1982, 1983, Pitcher 1988, Modin et al. 1996, Wilson \& McCormick 1997, 1999). These changes take the form of a rapid narrowing of increment widths, a change in the contrast of the increments and/or a zone of narrow, faint increments (Wilson \& McCormick 1997, 1999). It is of interest to know whether delay of metamorphosis leaves a signature, be it biochemical or structural. Since the deposition of increments appears to respond to settlement it is hypothesised that it is also likely to respond to a delay in metamorphosis in a characteristic way. One of the goals of this study was to examine whether fish do leave a signature of delay in their otoliths. If so, this fact may be used to gain a broader appreciation of the importance of delays in metamorphosis to the settlement dynamics of demersal fishes.

The present study examines the metamorphosis of the manini (or convict surgeonfish) Acanthurus triostegus (Acanthuridae) and its capacity to delay metamorphosis. Fish were caught as they colonised remote reefs in French Polynesia and the variability in their larval duration is examined. The metamorphosis associated with settlement into the benthic population is described as a precursor to a field experiment that examines the capacity of this species to delay metamorphosis. This study highlights that metamorphosis is an intricate and multilayered process in this species, with the timing being at least partly influenced by cognitive control.

\section{MATERIALS AND METHODS}

Sampling. Manini were collected from 2 geographic localities in French Polynesia to examine the structural changes that occur at metamorphosis and the levels of variation in larval duration. The 2 localities, Rangiroa Atoll in the Tuamotu Archipelago $\left(15^{\circ} 0^{\prime} \mathrm{S}, 147^{\circ} 54^{\prime} \mathrm{W}\right)$ and Raiatea-Tahaa $\left(16^{\circ} 85^{\prime} \mathrm{S}, 151^{\circ} 54^{\prime} \mathrm{W}\right)$ in the Society Archipelago, are $500 \mathrm{~km}$ apart and potentially seeded by different larval sources (Planes 1993).

Manini were collected on the reef crest at night using plankton nets $(3.5 \mathrm{~m}$ wide, $1 \mathrm{~m}$ high, $5 \mathrm{~m}$ long of $1 \mathrm{~mm}$ mesh) fixed to the substratum, similar to that used by Dufour et al. (1996). Fish were collected in a 3-part cod end which sorted the fish into 3 size classes ( $<5 \mathrm{~mm}, 5$ to $35 \mathrm{~mm},>35 \mathrm{~mm}$ body depth). At Rangiroa, a crest net was positioned in a hoa or channel through which water entered the lagoon. At RaiateaTahad, 2 crest nets were attached to the reef flat on the leeward side of the central lagoon between islands. Crest nets were $400 \mathrm{~m}$ apart and filtered water as it flowed over the reef crest into the lagoon.

Larval duration. The larval durations of manini collected from both locations were determined by counts of increments on sectioned sagittal otoliths. Sagittae were processed as per Wilson \& McCormick (1997). The number of increments on otoliths was counted 4 times in random order. Otoliths on which counts ranged over 5 or more increments were further polished and re-counted. In total 8 samples of manini 
were collected and processed for larval duration, representing 90 fishes. These increments were validated as being laid down on a daily basis by keeping 8 manini confined for a known period of time from settlement and comparing the number of days' confinement to the number of increments deposited on the otoliths. These fish were confined in benthic cages (described below) for $5 \mathrm{~d}$, followed by a further $10 \mathrm{~d}$ in a $150 \mathrm{l}$ outdoor aquarium supplied by flowing seawater. Of these 8 fish, increments were clearly discernible at the otolith edge for only 6 fish. Counts from the settlement check to the edge for these fish, confined for $15 \mathrm{~d}$ (14 nights), averaged 14.5 (SE 0.33). This result, together with the almost universal finding of daily increment formation in juvenile fishes, suggests that manini are depositing daily increments on their otoliths.

Randall (1961) described the embryonic development and early larval stages of the manini from Hawaii. He found that at a temperature of 24 to $26^{\circ} \mathrm{C}$ larvae hatched at ca $1.7 \mathrm{~mm}$ in length, $26 \mathrm{~h}$ after fertilisation. Since the first increment on the sagitta is often timed with hatching, 1 extra day was added to ages estimated from counts of increments on cross sections of the sagitta to account for embryonic development.

Metamorphosis of morphology. Metamorphosis was quantified by using a $\mathrm{Hi}-8$ video camera to record images of 6 individual fishes over the first 6 to $10 \mathrm{~d}$ of post-settled life. Crest nets were deployed at dusk in a hoa on Rangiroa atoll and the manini larvae were cleared from the net at 21:30 h. These were brought back to the laboratory, anesthetized with MS222 and placed into a small, narrow aquarium $(3 \times 15 \times 12 \mathrm{~cm})$. Fish were carefully restrained against the front of the aquarium by an extra piece of glass and a series of video images were captured against a scale bar. These images could then be digitised using a computer image-grabber (Mediagrabber) and imported into an image analysis package (NIH Image) to quantify various morphological variables. Fish were kept in individual tanks, fed Artemia sp. nauplii and video-taped once a day for 6 to $10 \mathrm{~d}$.

The 11 morphological variables recorded from the video images are shown in Fig. 1. For each fish the ventral body angle and angle of the dorsal surface of the head were measured 3 times and the average angle was used in analyses. To examine the change in body dimensions over time, the linear body measurements were expressed as a proportion of the standard length when first captured.
To determine the precision of quantifying morphology from live specimens using the video technique described, a pilot study was undertaken. This involved the capture of 10 images from video footage of 5 manini (i.e. 10 images each), measuring the 11 morphological variables on each image and examining the extent to which the measures varied among images. Average coefficients of variation were low for all measures, ranging between $0.32 \%$ (total length) to $4 \%$ (eye diameter), with a median of $1.27 \%$, suggesting that morphology could be precisely described using this methodology.

Can manini delay metamorphosis? To address this question, fish were placed in 2 types of cage treatments. The first cage type was attached to the benthos in a habitat where juveniles are found naturaily and was simply to keep fish of known settlement history in a natural settlement habitat (benthic cage). The second cage type was a fine meshed cage suspended off the reef in an attempt to convince the fish that they were still in the pelagic environment (pelagic cage). Fish caught in the crest nets were removed between 03:00 and 04:00 $\mathrm{h}$, some 2 to $3 \mathrm{~h}$ after the change in tide and setting of the moon. Manini were carefully sorted from the general catch of fish and randomly assigned to 1 of the 2 cage treatments. The benthic cage treatment consisted of a fibreglass mesh cage $(0.8 \times 0.8 \times 0.8 \mathrm{~m}$

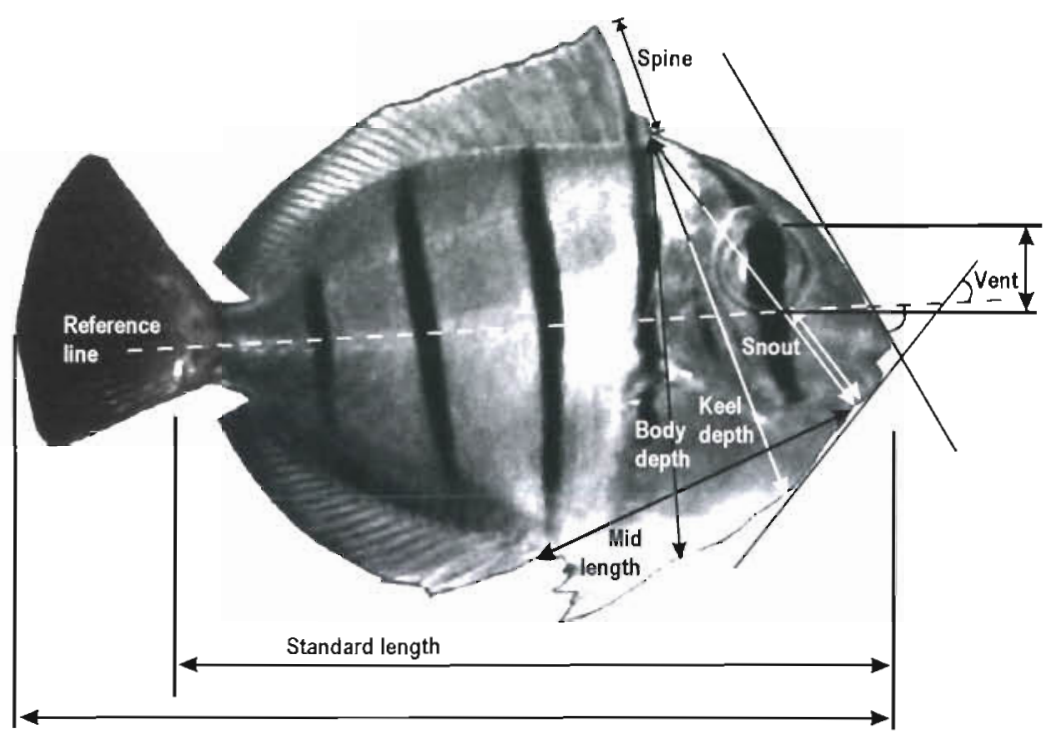

Fig. 1. Acanthurus triostegus. Morphological measurements made on captured video-images of live fish to assess morphological change during metamorphosis. Only the 6 measures used in the analyses of body form are labeled. These measures were: body depth, distance between the first dorsal spine and base of the pelvic fins; keel depth, distance from the first dorsal spine to a point midway between the dentary and base of the pelvic fins; mid length, distance between the dentary and anus; snout, distance between the first dorsal spine and dentary; spine, length of the second dorsal spine; standard length; vent, the angle of the ventral body to the body reference axis 
dimension, $2 \times 4 \mathrm{~mm}$ mesh size) positioned in $3 \mathrm{~m}$ of water on the backreef, $100 \mathrm{~m}$ from the reef flat. Corners of the cage were secured to $2 \mathrm{~m}$ metal starpickets driven into the reef base, while a mesh skirt at the base of the cage was weighed with metal rods and buried in sand and rubble. An access door at the top of the cage allowed fish introduction and removal. The cage floor was covered with sand and rubble, consistent with the substratum newly settled fish frequent (Randall 1961, pers. obs.). The pelagic cages consisted of fine monofilament mesh cylinders $(3 \mathrm{~m}$ high $\times 1 \mathrm{~m}$ diameter, $10 \mathrm{~mm}$ mesh) suspended by hoops from a subsurface buoy at $6 \mathrm{~m}$ depth and anchored midway down the first outer reef slope at $30 \mathrm{~m}$. From here the slope drops away abruptly to $50 \mathrm{~m}$, slopes gradually to $70 \mathrm{~m}$ (in a distance of about $100 \mathrm{~m}$ ) and then drops precipitously to ca $1200 \mathrm{~m}$. Cages in both treatments were cleaned at least once daily. Three independent trials of between 8 and 15 fish per cage were run.

At the end of $5 \mathrm{~d}$, fish from each trial were removed from the 2 cage types and brought back to the laboratory live. To determine whether there was a difference in the degree of metamorphosis between the cage treatments, all fish were video-taped from the side (as above) with a scale bar and details of the degree of body transparency were noted. Later, images of each fish were digitised by computer and the 11 morphological variables (shown in Fig. 1) were measured. For the first 2 trials, 4 fish from each treatment were preserved in $10 \%$ formalin in seawater for histological examination, while the remainder were placed in $70 \%$ alcohol for otolith examination. All fish were weighed prior to preservation. Once weighed and video-taped, fish from the last trial were subject to further experimentation (below).

Effect of delay on otolith increment microstructure. To examine the influence of extended larval durations on otolith growth, sagittae were cross-sectioned (as above) and the mean increment trace of the 3 manini with the longest larval durations was compared to the mean trace from the 3 manini with the shortest larval durations. Increment widths were measured along a transect over the longest axis of the otolith transverse section using a computer image-analysis package linked to a compound microscope.

To investigate how delaying metamorphosis influenced the microstructure of the otolith increments, fish in the last trial from both benthic and pelagic treatments were kept alive in a benthic habitat for a further $10 \mathrm{~d}$ after being $5 \mathrm{~d}$ in the cage treatments. In this trial, once fish had been video-taped, they were individually tagged and kept in a $150 \mathrm{l}$ outdoor aquarium supplied with running seawater. Rubble covered with filamentous algae was placed daily in the tank to feed the juveniles. Fluorescent elastomer (Northwest Marine
Technology Inc.) tattoos were used to individually identify fish. After $10 \mathrm{~d}$ fish were stored in $70 \%$ alcohol until otoliths were processed. One sagitta from each fish was sectioned and increment widths were measured. Increment traces each side of the settlement mark of fish from the 2 cage treatments were compared to those of wild-caught juvenile manini. These measurements were taken along a transect over the shorter side of the main axis of the otolith section, since post-settlement increments were consistently more readable in this orientation.

Analyses. A principal component analysis (PCA) (on the correlation matrix) was used to compare the body morphology of Acanthurus triostegus, collected from 3 sources: (1) transparent, non-metamorphosed fish that had been video-taped for morphometric measurement within $2 \mathrm{~h}$ of capture in the crest nets; (2) fish that had been confined within the benthic cages for $5 \mathrm{~d}$ and then video-taped for morphometric measurement $_{i}$ (3) fish that had been confined within the pelagic cages for $5 \mathrm{~d}$ prior to being video-taped. Linear body dimensions were converted to proportions of standard length prior to analysis. The original 11 variables were reduced to the 6 used in analyses by 3 methods: graphical examination of the trends in the variables over metamorphosis (as above) was used to identify important variables; colinear variables were dropped; variables that scored highest on the last component of a preliminary PCA were dropped. The PCA was interpreted in relation to the original body variables by plotting the eigenvalues as eigenvectors from the origin (euclidean distance biplot). The relative length and direction of these vectors indicates the direction and importance of trends in the original variables. To investigate whether the pelagic-caged fish maintained a nonmetamorphosed body morphology, 2 cluster analyses were undertaken on this morphological dataset (average linkage and Ward's hierarchical cluster analyses, SAS Institute Inc. 1987). Results of these cluster analyses were superimposed onto the plot of the first 2 components of the preceding PCA.

A discriminant function analysis (DFA) was used to investigate the extent to which fish could be classified on the basis of morphology to 1 of 2 categories: non-metamorphosed (source 1 above) and metamorphosed (source 2 above). This analysis produced a set of analytical rules that discriminated between these 2 groups of fish. These rules where then used to classify the pelagic-caged fish (source 3 above) into either the metamorphosed or non-metamorphosed groups based on morphology. The same 6 morphological variables used in the PCA above were used in this analysis, with linear measures standardised by standard length. 


\section{RESULTS}

\section{Larval durations}

There was a relatively low level of variability in larval duration amongst samples of manini collected at colonisation (Fig. 2a), with an overall coefficient of variability of $5.5 \%$. An analysis of variance showed that there was 4 times the variability in pelagic larval duration (PLD) among individual fishes within samples as there was amongst samples $(80$ and $20 \%$ respectively). Samples differed from one another over short time-scales $\left(F_{7,89}=3.71, p<0.0016\right)$, although these differences were small. Overall, the sample of larval durations was normally distributed (Fig. 3) with a medium age of $53 \mathrm{~d}$, ranging from 44 to $60 \mathrm{~d}$.
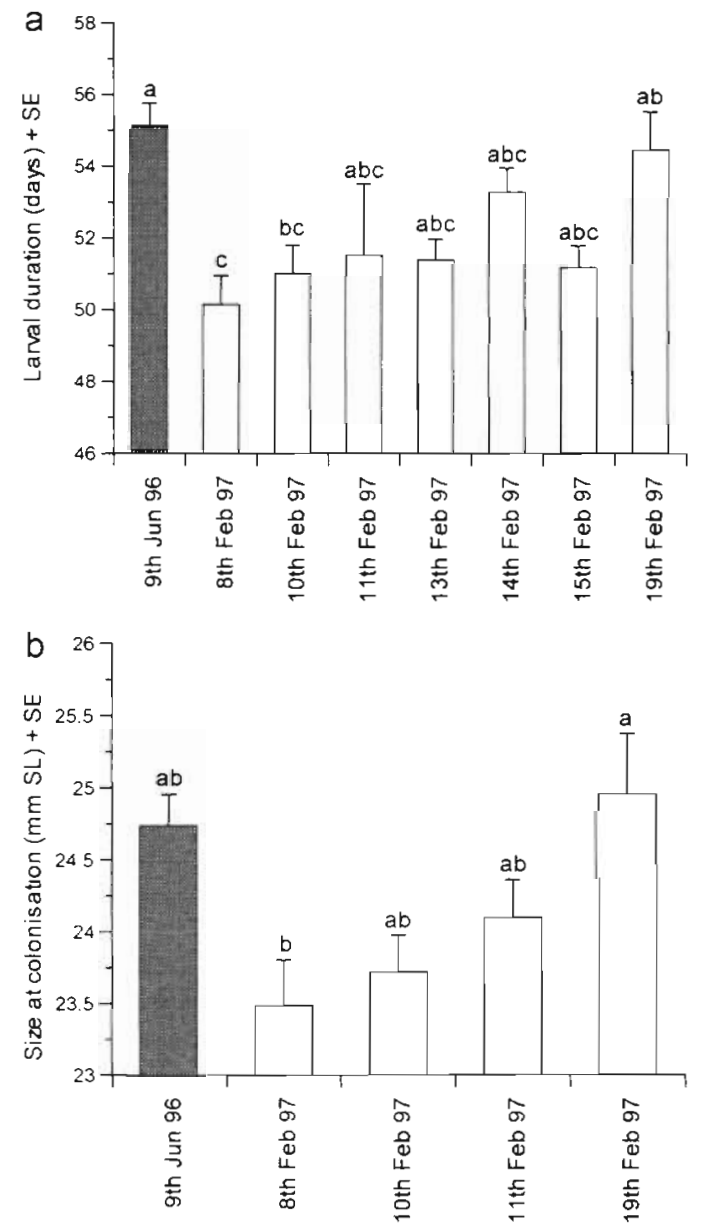

Fig. 2. Acanthurus triostegus. (a) Larval duration of 8 samples of fish collected from crest net samples in French Polynesia. (b) Standard length at colonisation of 5 samples of fish. Results of Tukey's (HSD) means comparisons are given; bars with the same letters are not significantly different (at $\mathrm{p}<$ $0.05)$. The shaded sample represents that collected at Rangiroa Atoll, while other samples were collected from RaiateaTahaa (as per text)

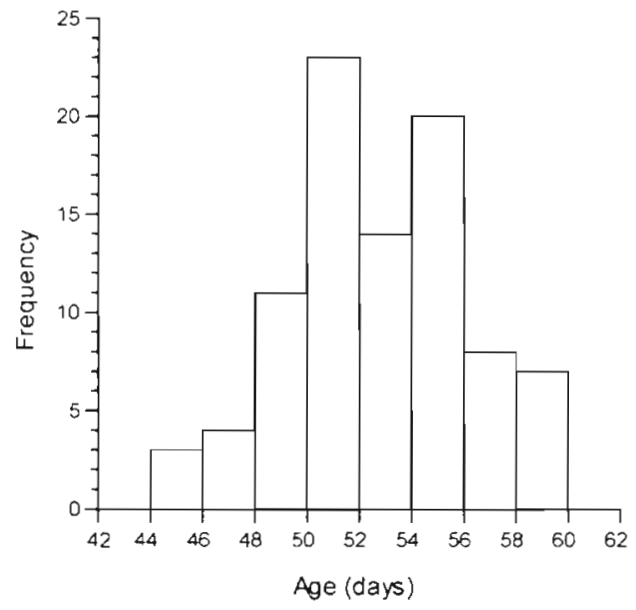

Fig. 3. Acanthurus triostegus. Distribution of Larval durations of A. triostegus from French Polynesia $(n=90)$

Size at colonisation varied little among the 5 samples for which size data were available. Fish size ranged from 22.3 to $26.1 \mathrm{~mm} \mathrm{SL}$, with an overall coefficient of variability of $3.7 \%$. Despite this small size range there was a significant difference in mean standard length among the 5 samples of fish $\left(F_{4,36}=4.28, p=0.006\right.$, Fig. 2b).

\section{Metamorphosis}

When first caught in the crest nets, the manini were transparent with a silver lining over the brain case, alimentary tract and swim-bladder (Fig. 4). Within $2 \mathrm{~h}$, 6 faint black stripes developed on the lateral surfaces and the fish began to lose their transparency. After $24 \mathrm{~h}$, these black stripes were well developed and fish had lost most of their transparency except for the outline of the vertebral column being visible.

There was a $24 \%$ reduction in the length of the second dorsal spine over the first $8 \mathrm{~d}$ after colonisation (Fig. 5). Body depth at the base of the pectoral fin showed a $12 \%$ reduction in the first $5 \mathrm{~d}$, followed by another $6 \%$ reduction between Days 7 and 9 (Fig. 5). The latter may be a function of the small number of fish observed for longer than $6 \mathrm{~d}$. The angle of the top of the head to the main body axis showed no change, while the angle of the ventral body showed a linear reduction of $14^{\circ}$ over the $9 \mathrm{~d}$ observation period (Fig. 5). The keel depth showed a $15 \%$ drop in length over the first $5 \mathrm{~d}$ before stabilising (Fig. 5). In summary, the fishes become less discoid over time, by the mouth moving from a terminal to a ventral position (Fig. 4). The osteological re-organisation of the head that accompanies this transformation was not examined in the present study 

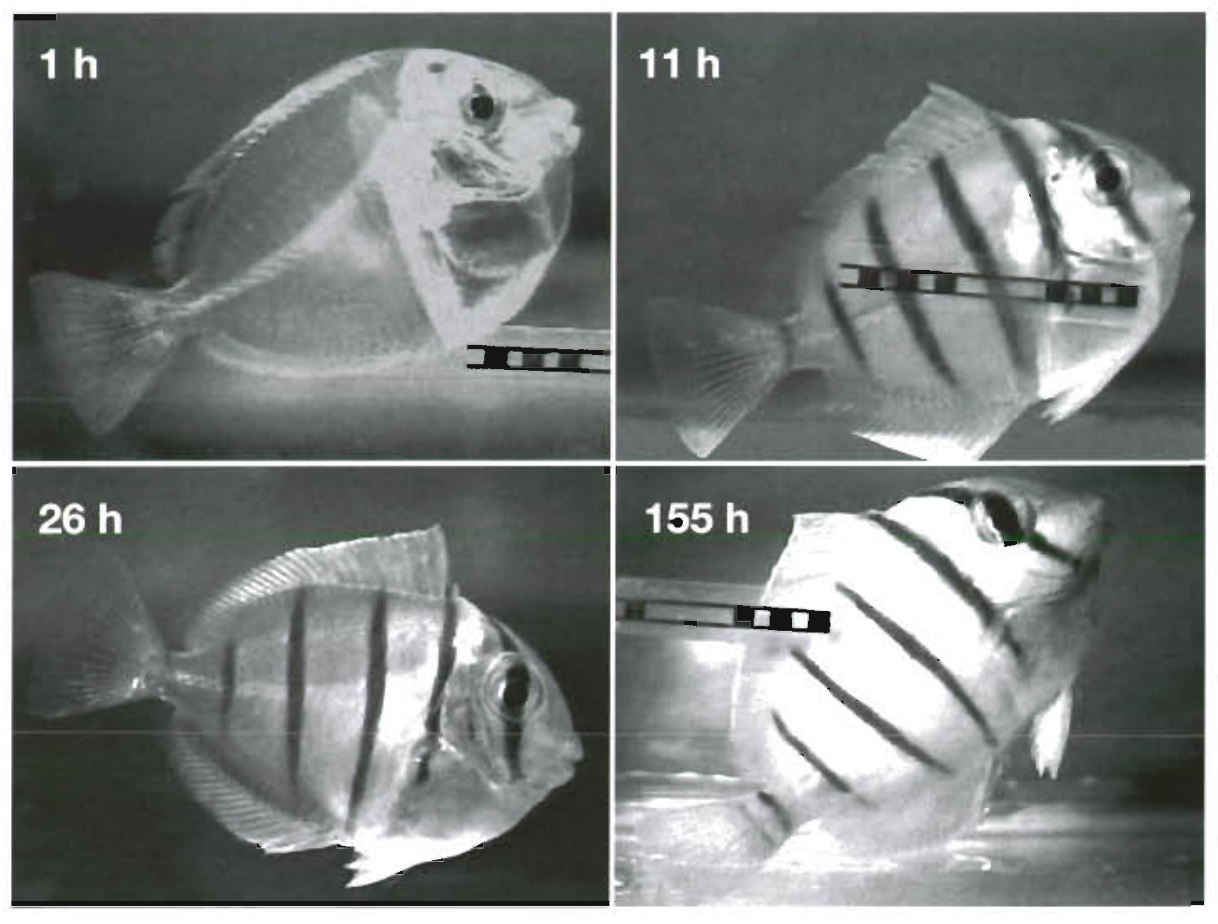

Fig. 4 Acanthurus triostegus. Photographic series showing the metamorphosis of $A$. triostegus obtained from video images of live fish. Minor divisions in scale bars represent $1 \mathrm{~mm}$
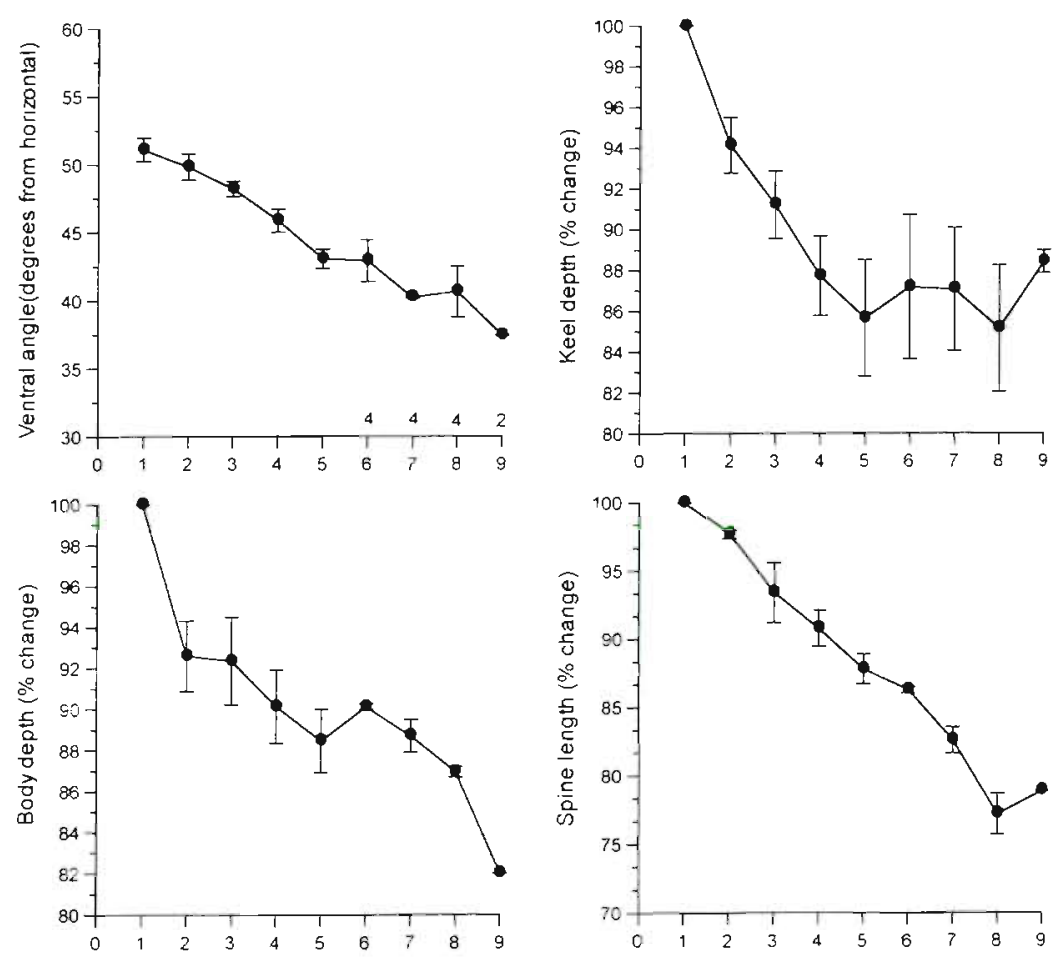

Days post-colonisation

Fig. 5. Acanthurus triostegus. Changes in magnitude of 4 morphological variables detailing the metamorphosis of $A$. triostegus over a $9 \mathrm{~d}$ period. Linear measures are expressed as proportional changes from lengths obtained from video images immediately after capture in crest nets

\section{Can manini delay metamorphosis?}

In all 3 trials of the experiment, all fish in the benthic cages had developed stripes and lost transparency by the middle of the morning following the start of the experiment. All fish started to forage over the rubble substrata, although some spent periods hiding in the corners of the cages during the first day after colonisation. Fish in the pelagic cages had a more variable response: with a gradation between fully metamorphosed to non-metamorphosed. Approximately $20 \%$ of the fish metamorphosed completely in the pelagic cages and could not be distinguished from fish in the benthic cages at the end of the $5 \mathrm{~d}$ trials. The majority however, maintained some level of transparency and developed faint stripes characteristic of fish ca $2 \mathrm{~h}$ postcolonisation.

A principal component analysis of the body dimensions of fish from the benthic cages, the pelagic cages and a sample of non-metamorphosed fish (immediately video-taped upon capture) illustrates the variable response of manini to the 


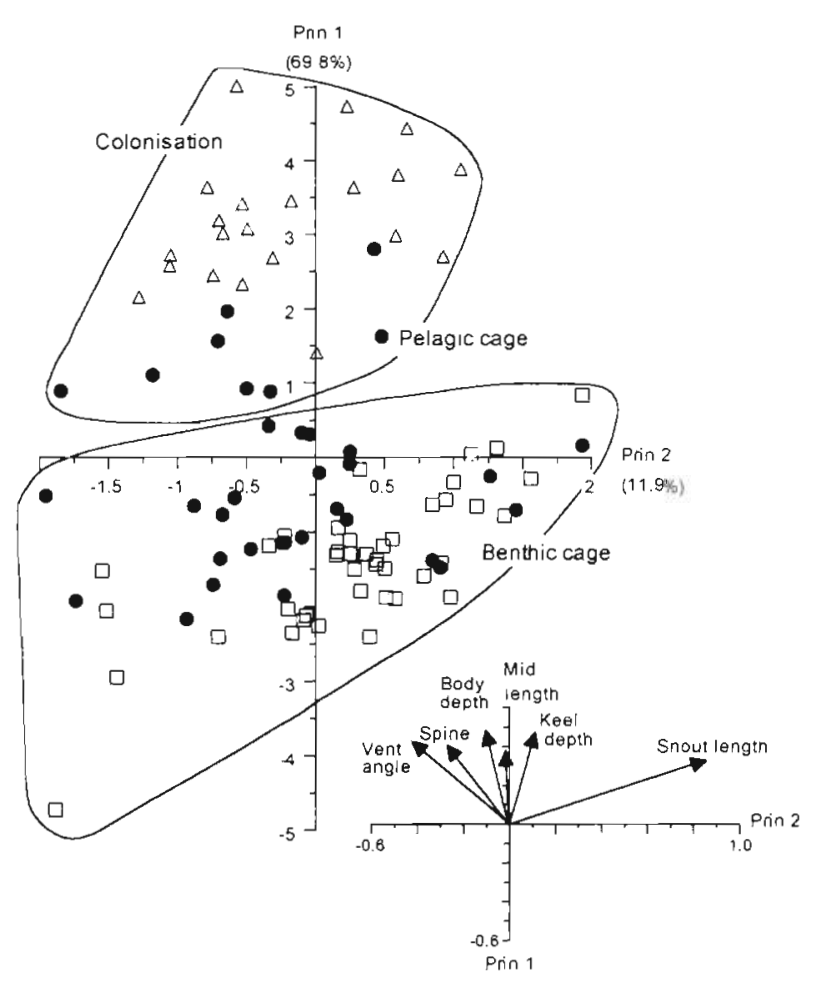

Fig. 6. Acanthurus triostegus. Comparison of the morphologies of $A$. triostegus from 3 sources: $(\Delta)$ transparent, nonmetamorphosed fish, video-taped for morphometric measurement within $2 \mathrm{~h}$ of capture in the crest nets; (D) fish confined in benthic cages for $5 \mathrm{~d}$ prior to measurement; ( fish that had been confined in pelagic cages for 5 d prior to measurement. The results of a cluster analyses have been superimposed on a principal component analysis which displays the pattern of variability in body morphology (expressed by 6 variables, as per inset) among the fish (shown in Fig. 1). Each symbol represents an individual fish. The vector diagram (inset) shows the trends in the original body variables that explain the differences among individuals
A discriminant function analysis (DFA) supports these results. A DFA was able to create new axes from the original body dimensions that absolutely (i.e. $100 \%$ success) discriminated between non-metamorphosed fish and the benthic caged fish at the end of the experiment (Pillai's Trace $=0.938$, df $=6,55, p=0.0001$ ). When the pelagic caged fish are used as a test set, 8 out of 34 fish were classified as non-metamorphosed fish on the basis of body dimensions. These were the same individual fish as those grouped with the nonmetamorphosed fish in the cluster analyses.

\section{Growth and delayed metamorphosis}

Fish in the pelagic cages that were found to be similar in body dimensions to non-metamorphosed fish at the end of the experiment also had slower growth rates than fish within the benthic cages (Fig. 7). The 8 nonmetamorphosed fish from the pelagic cages averaged $25.6 \mathrm{~mm} \mathrm{SL}$ at the end of the $5 \mathrm{~d}$ experiment. These were significantly smaller than both fish within the pelagic cages that had a higher degree of metamorphosis (26.54 mm SL) and those fish in the benthic cages $\left(26.8 \mathrm{~mm} \mathrm{SL}, F_{2,74}=8.61, \mathrm{p}<0.0004\right)$. Since random samples of fish were placed into the pelagic cages, this suggests that growth over the experiment was lower in those fish that did not undergo metamorphosis in the pelagic cages.

There was no relationship between growth rate at the end of the larval stage and the rate at which experimental fish underwent metamorphosis (Fig. 8). The first principal component of the body dimension analysis was used as a relative measure of the extent of metamorphosis (Fig. 6), while the overall width of the pelagic cage treatment (Fig. 6). The 3 samples separate largely on the first principal component. A vector diagram of original body dimensions suggests the variables most influential in this separation are the same as those most influenced by metamorphosis (Fig. 6 inset), namely keel depth, body depth, 2nd dorsal spine length and ventral body angle.

The results of 2 cluster analyses (Ward's and Average Linkage) are superimposed on the PCA (Fig. 6). Both gave exactly the same Iesults, with the cubic-clustering-criterion identifying 2 clusters. The first of these clusters involved all the non-metamorphosed fish, together with 8 of the 34 fish that had been in the pelagic cages for $5 \mathrm{~d}$. The second cluster included all fish from the benthic cages, together with the remaining pelagic-caged fish.

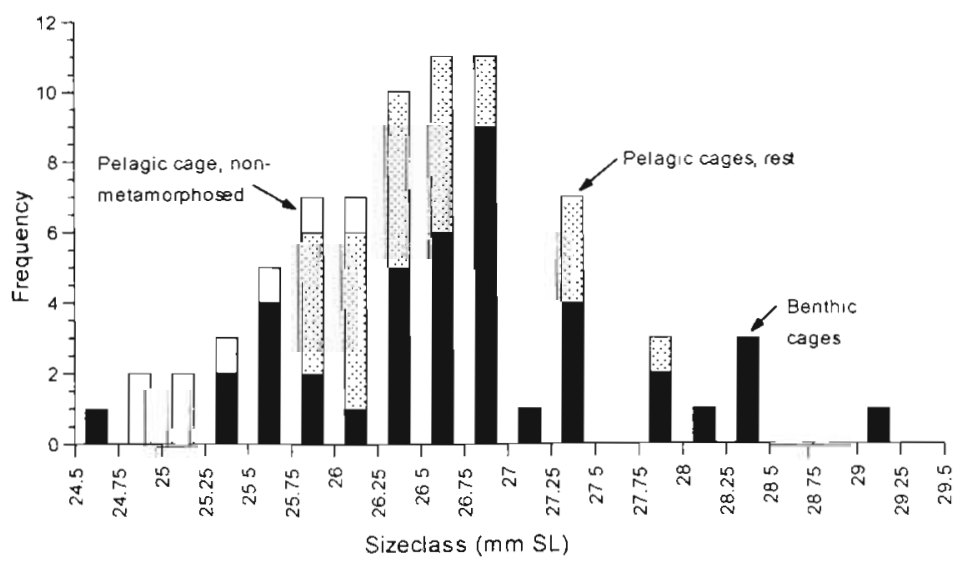

Fig. 7. Acanthurus triostegus. Size-frequency comparison for fish from pelagic and benthic cage treatments. Fish from pelagic cages are divided into those that were not statistically different from newly collected, nonmetamorphosed fish, and those that showed morphological affinities to metamorphosed juveniles (as indicated in Fig. 6 and accompanying text) 


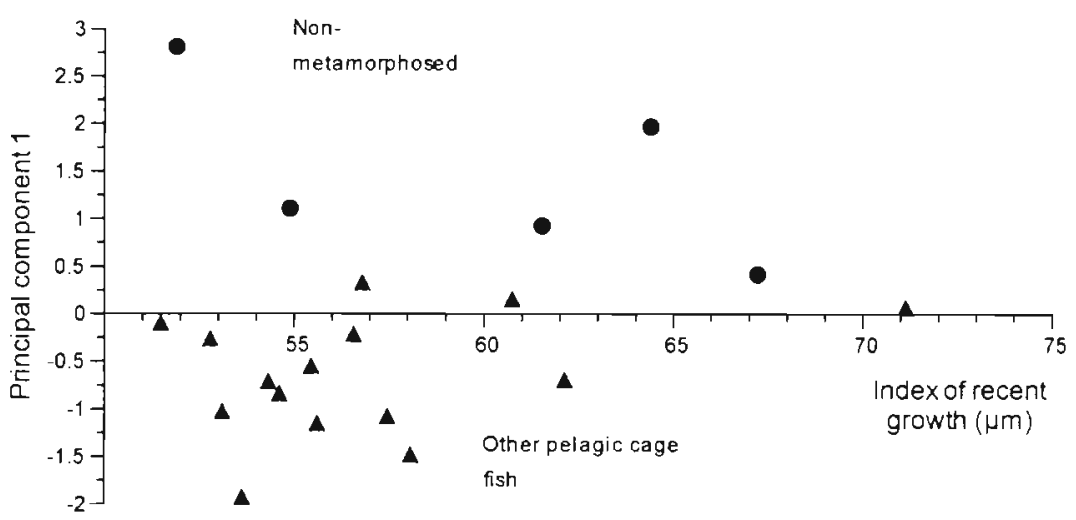

Fig. 8. Acanthurus triostegus. Influence of recent pelagic growth history on the propensity to delay morphological metamorphosis. The first component of the previous PCA (Fig. 6) is used as an index of the degree of metamorphosis, while the width of the last 7 increments on sagittal cross-sections is used as an index of the magnitude of recent larval growth (this is believed to be a conservative measure of recent growth history, Suthers et al. 1989)

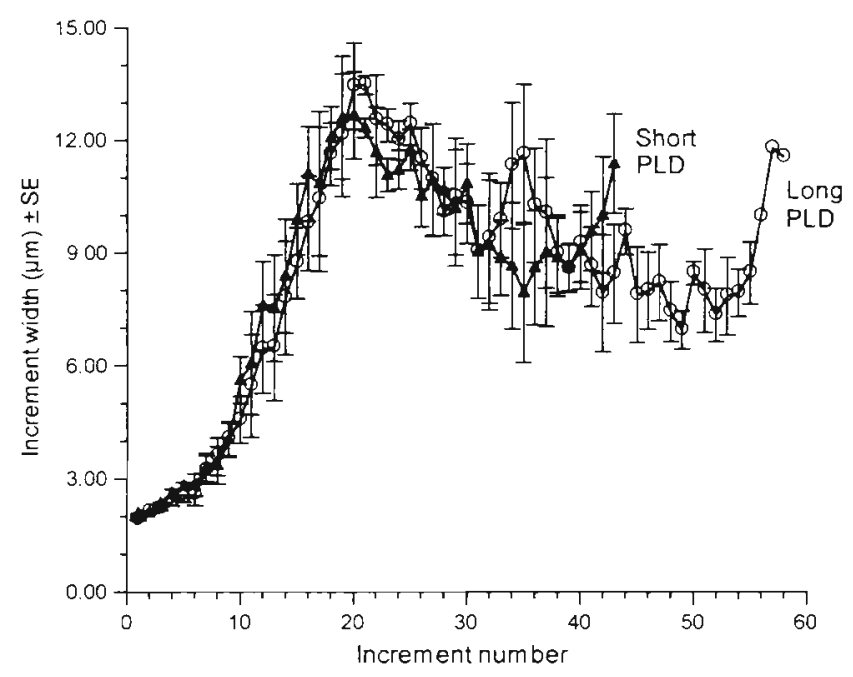

Fig. 9. Acanthurus triostegus. Growth history of the sagittal otoliths, expressed as average increment widths, from 3 A. triostegus with the shortest and longest pelagic larval durations (PLDS) last 7 increments prior to the start of the settlement mark on the sagittal otolith was used as a measure of recent pre-colonisation growth history. The 5 nonmetamorphosed fish from the pelagic cages that were aged (since some were placed in formalin) had increment widths that spanned the range encompassed by the pelagic-cage fish that were in a more advanced state of metamorphosis. These data suggest that latelarval growth rate had little bearing on the speed with which fish underwent metamorphosis.

To examine whether there was any difference in growth history between fish with the shortest and longest larval durations, the increment-width profiles of the 3 oldest and youngest fish at colonisation were compared (Fig. 9). All fish showed a peak in increment width $20 \mathrm{~d}$ post-hatching, followed by a reduction in increment width until 4 or $5 \mathrm{~d}$ prior to colonisation (Fig. 9). Fish that displayed the longest larval durations had a longer period of reduced otolith growth just prior to colonisation than those with short larval durations.

For some fish, the rate of growth of the otolith, as measured by increment widths, increased just prior to colonisation. When the last 20 increment widths from the profiles are plotted in relation to the time of colonisation (Fig. 10), it becomes obvious that the growth histories of the 2 groups of fish are very similar prior to settlement, but the fish with the short PLDs have consistently larger otolith increments.

Fish that were caught at colonisation had no indication of a settlement mark on the margin of the otolith sections Fish that were kept in both the pelagic and benthic cages had settlement marks on their otoliths, suggesting that the process that initiated the change in otolith growth trajectory had been initiated in the pelagic-caged fishes despite being
Fig. 10. Acanthurus triostegus. Comparison of profiles of the last 20 increments deposited on the $3 \mathrm{~A}$. triostegus with the lowest and highest pelagic larval durations (PLDs) 
suspended in the pelagic environment (Fig. 11). Those fish that maintained pelagic morphology and colouration at the end of the pelagic-cage treatment and were then placed into a grow-out tank (trial 3) rapidly attained juvenile colouration and morphology. Differential mortality of fish from this trial meant that only 1 pelagic fish that delayed metamorphosis survived the $10 \mathrm{~d}$ period (4 out of 5 pelagic-caged fish died, while all

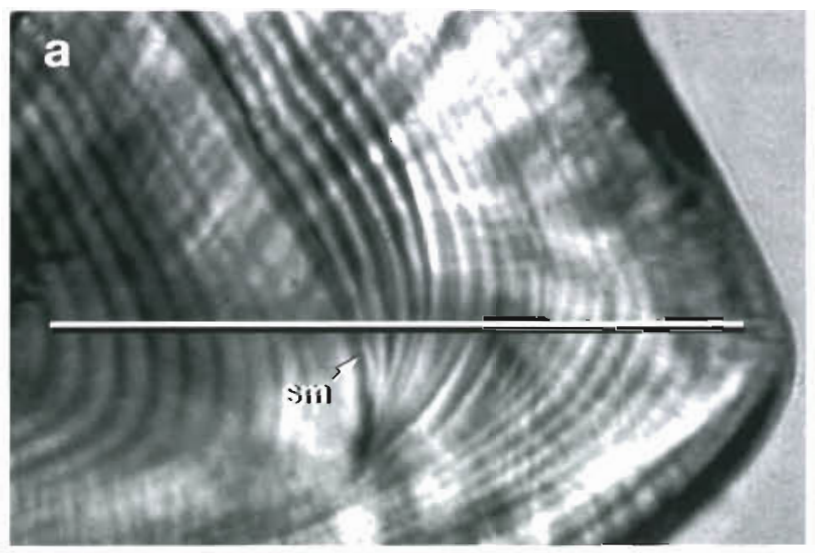

b

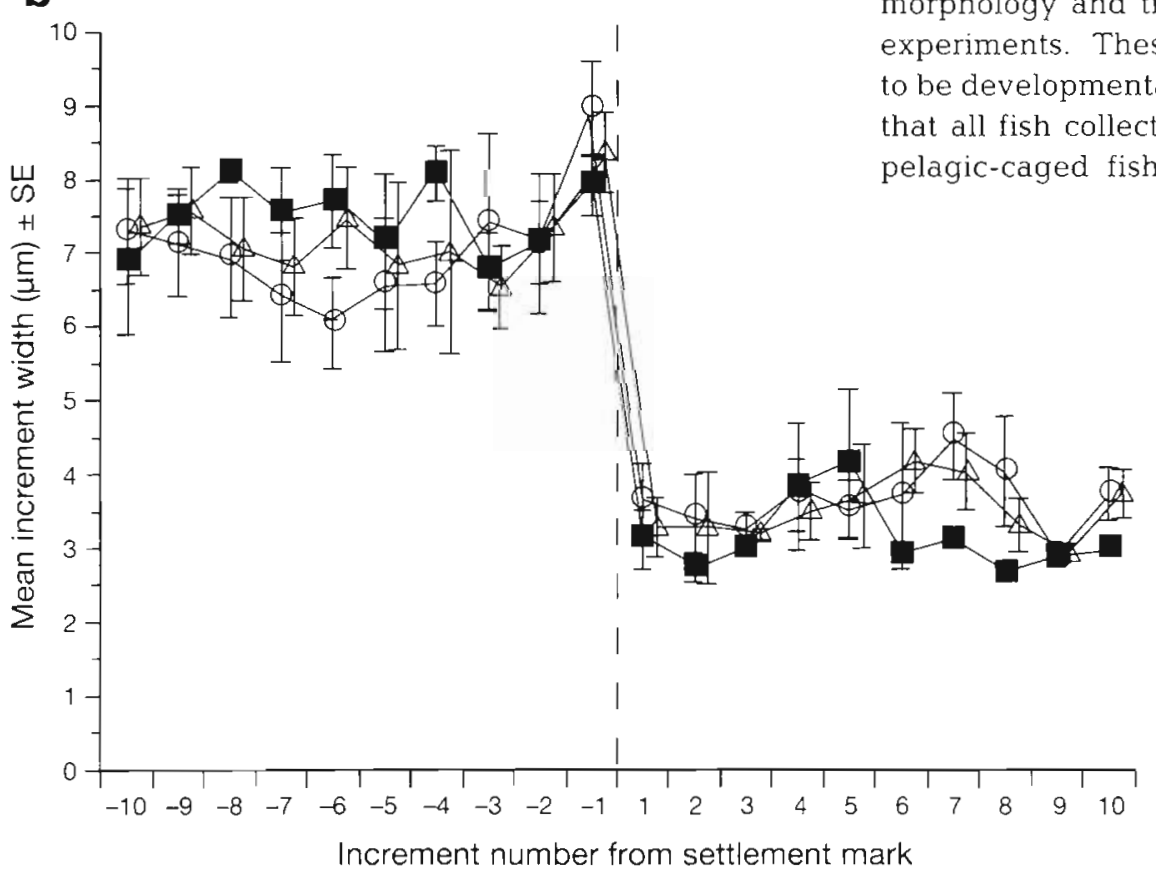

Fig. 11. Acanthurus triostegus. Comparison of settlement mark structure in the sagittal otoliths of A. triostegus among reef-caught juveniles and benthic-and pelagic-caged fish. (a) Micrograph showing the settlement mark in a juvenile and the location of the increment width transect. (b) lncrement width profiles of reef-caught juveniles (•), manini kept in benthic cages for $5 \mathrm{~d}$, then in a $150 \mathrm{l}$ tank for a further $10 \mathrm{~d}$ ( $\mathbf{4}$ ) and manini kept in pelagic cages for $5 \mathrm{~d}$ that delayed metamorphosis ( $\mathbf{m}$ ). The increment trace from the sole surviving manini that delayed metamorphosis for $5 \mathrm{~d}$ and was kept for a further $10 \mathrm{~d}$ is included with the pelagic-caged fish $(\mathrm{n}=3$ for all traces, except for the last 5 increments of the pelagic-caged fish, where $n=1$ )
12 benthic-caged fish survived). Examination of otolith increments around the time of metamorphosis and settlement suggests that delaying metamorphosis did not influence the structure of the settlement mark (Fig. 11). Cross-sections from the otoliths of reefcaught juvenile manini showed that the settlement mark was characterised by a dense increment, followed by a slight change in the growth plane of the otolith. Examination of the otolith profile of the 1 fish that had delayed metamorphosis and was This may be because stress associated with nd manipulation caused a check mark in the mark

\section{DISCUSSION}

This study is the first to conclusively demonstrate that a demersal fish species has the capacity to delay metamorphosis. Twenty-four percent of the manini that were caught at colonisation and forced to re-enter their pelagic environment maintained their late-larval morphology and transparency over the course of the experiments. These experimental fish were shown at exactly the same time as the nd placed on a suitable settlement substrata in the lagoon, immediately metamorphosed and attained their juvenile form. These results are consistent with the conceptual model of fish settlement that has been developed from research on invertebrate metamorphosis (e.g. Crisp 1974, Jackson \& Strathmann 1981, Pecknick 1990, Davis 1994) and to date has largely been assumed rather than demonstrated by fish ecologists.

It is interesting that some of the manini placed in the pelagic cages immediately upon capture in the crest nets developed stripes characteristic of a manini 2 h after settlement, while maintaining both the transparency of their soma and pelagic morphology. The observation that if fish are left in a crest net they are well into their metamorphosis by morning suggests that by swim- 
ming in close proximity to the reef during colonisation they have already been exposed to the cues necessary to stimulate metamorphosis. Despite this, these fish managed to delay morphological transformation. This decoupling of a pigment change from other aspects of metamorphosis suggests that all components of the transformation may not be triggered at the same time (or possibly even by the same cue) and that metamorphosis may be suspended in its early stages.

Variation in the PLD among the 8 samples of manini collected over a 2 yr period was very low (CV 5.5\%) considering the species' pan-Pacific distribution (Randall 1961). Collections spanned 2 geographic areas (Raiatea-Tahaa and Rangiroa) that have been shown to have a moderate level of genetic isolation in an allozyme study of the species (Planes 1993), which may be expected to promote divergence in PLD among localities. These findings of low variability are similar to those of Randall (1961) who studied manini in Hawaii and roughly estimated larval duration by the difference between the timing of the first ripe female and the first incoming juvenile. He obtained PLD estimates of between 71 and $83 \mathrm{~d}$, similar to the $16 \mathrm{~d}$ range found in the present study. Interestingly, the length of the larval duration was much greater for the Hawaiian manini than for those from French Polynesia (at 44 to $60 \mathrm{~d}$ ). This may be because the Hawailan fish were undergoing considerable delays in metamorphosis and settlement. Alternatively, it may also be due to selection for a higher average larval duration in the Hawaiian population. The broad size distribution of fish Randall caught on the day of settlement ( 22 to $29.5 \mathrm{~mm} \mathrm{SL}$ ) compared to the restricted size distribution found in this study (22.3 to $26.1 \mathrm{~mm} \mathrm{SL}$ ) suggests that the higher Hawaiian mean PLD may be due in part to delayed metamorphosis. This suggests that although the fish may not use its capacity to delay to a great extent, the potential to delay gives it added flexibility in putting off metamorphosis until the appropriate cues are forthcoming (Cowen \& Sponaugle 1997). The potential to delay metamorphosis, and the potentially lengthy larval durations it confers, is likely to have maintained the broad genetic integrity of the species across the Pacific Basin.

Most studies showing some evidence of delayed metamorphosis have found that larval durations that extend well beyond the average are rare. Victor (1986) and Masterson et al. (1997) found that less than $1 \%$ of the bluehead wrasse examined had extended larval durations. In studies where extended larval durations are more common, fish have usually been collected far from their spawning grounds (Cowen 1991, Jenkins \& May 1994, Fowler \& Short 1996), or have very specific temporal settlement cues (e.g. specific lunar phase, Sponaugle \& Cowen 1994). Sponaugle \& Cowen (1996), studying the Caribbean surgeonfish Acanthurus bahi- anus, found no evidence of extended larval durations from a sample of 68 light-trap-caught fish collected over a 2 yr period. The lack of evidence for extended larval durations for surgeonfish in this and the present study may be due to the well developed pelagic-juvenile (sensu Leis \& Rennis 1983; or acronurus) life stage, which is particularly well developed in the Acanthuridae. Settlement-stage surgeonfish have a well developed swimming ability (Leis \& Carson-Ewart 1997, Sancho et al. 1997, Stobutzki \& Bellwood 1997) and remarkable stamina, enabling forced swims of up to $100 \mathrm{~km}$ under laboratory conditions (Stobutzki \& Bellwood 1997). It may be that manini have such a highly developed swimming capability and ability to navigate to reefs that they seldom need their capacity to delay metamorphosis. As Cowen \& Sponaugle (1997) note, even when the ability for delay exists in a species, it will not always be required and may only be expressed under rare environmental conditions.

Manini in the pelagic-cage treatment that delayed metamorphosis grew less over the $5 \mathrm{~d}$ experiment than either fish in the same treatment that were in more advanced stages of metamorphosis, or fish from the benthic-cage treatment. This may be because these late-larval-stage fish have very low feeding rates. Randall (1961) found that 45 of the 58 late-larval-stage Acanthurus triostegus he collected around lights at night had empty guts. He also noted that all newly settled fish he collected (30) were completely empty. It may be that the changes in the alimentary tract associated with the initial stages of metamorphosis may inhibit feeding. Reduced growth rates are often concomitant with extended larval durations in fish. Fowler \& Short (1996) found that 2 samples of newly settled King George whiting Sillaginoides punctata collected 3.5 mo apart differed in larval duration by $60 \%(80$ vs 131 d). Despite this major difference in larval duration, the sizes at settlement were similar. Victor (1986) found that bluehead wrasse which had extended pelagic durations also had slower growth after the modal age at settlement (calculated from his extensive sample of PLDs) had been attained. An exception to the generality of reduced growth is the Caribbean gobiid Coryphopterus glaucofraenum; this species has the capacity to extend its larval duration by a month whilst maintaining its growth rate, as inferred from otolith increment widths (Sponaugle \& Cowen 1994). Although the reduced growth rates found in fish that delayed metamorphosis in the present study fit the general pattern displayed by fish with extended pelagic durations, they may be an experimental artifact. The habits of late-larval-stage manini are unknown, but it is safe to assume that they forage widely in the water column. The reduced growth displayed by pelagic-caged fish may be because food was restricted 
to that floating through the cage, while fish in the benthic cage could readily feed on invertebrates and algae associated with the rubble inside the cage.

\section{Defining competence}

The main barrier to determining the importance of metamorphic delays to variation in PLD for fish is the difficulty in clearly defining when an individual has reached a state of developmental competence. Morphological criteria have been used to determine the generality in the occurrence of delayed metamorphosis in the field for marine invertebrates with some success (e.g. Emlet 1986, Fenaux \& Pedrotti 1988, Lipcius et al. 1990). Similarly, Holmes et al. (1994) successfully used specific minima of length and weight in spring to predict which lampreys (Petromyzontiformes) would metamorphose the following summer. Morphological criteria that characterise delay could not be reliably identified in the present study. Manini that delayed metamorphosis remained morphologically similar to those at colonisation by my morphological definition and characterisation of metamorphosis (Fig. 6). At present there is no known morphological alteration that confers competence in demersal fishes.

Despite some success with invertebrates, defining developmental competence to metamorphose is very difficult. In a review of the subject, Pechenik (1990) noted that competence in marine invertebrates has been defined to start: (1) after a certain amount of time; (2) when some larvae in a culture can be induced to metamorphose; (3) when a certain mean size is reached; and (4) when at least some larvae exhibit morphological or behavioural changes. Such definitions have been inadequate for all but the broadest demonstrations of delay. This is equally true of studies of metamorphosis in demersal fishes.

Victor (1986) and Masterson et al. (1997) avoided the issue of defining when an individual had attained competence. Instead, they classified those fish that made the age frequency distribution of newly settled bluehead wrasse right-skewed as having delayed metamorphosis. Sponaugle \& Cowen (1994) defined the competence of 2 species of Caribbean gobiid on the basis of being older at settlement than the youngest common age-class. Cowen (1991) suggested that individuals of a temperate wrasse were competent when they started to show reduced otolith growth. Jenkins \& May (1994) made a similar suggestion for the King George whiting off Australia. Cowen (1991) also used the minimum age at which a species settled as an approximation of the age at which the species became competent. This assumes that the variability in developmental rates that determine the age to competence are small and that most of the variability in PLD is due to delayed metamorphosis in the competent phase. This assumption remains untested.

In the present study, even those manini with the lowest PLDs showed extensive periods of reduced otolith growth, with the maximum increment widths being attained on Day 20 (Fig. 9). Otolith increment traces of the 3 oldest and youngest manini showed close correspondence until Day 30, after some $15 \mathrm{~d}$ of reduced otolith growth. Following this increment, traces began to show a great deal of individual variation. Wilson \& McCormick (1999) examined the increment traces of 44 species of tropical reef fish from 9 families and found that fish typically settled well after attaining their peak otolith growth. It may be that delaying metamorphosis is the norm for reef fishes, but given the duration between maximum increment width and settlement combined with the wide range of taxa studied, the widespread accurrence of delays is not the most parsimonious conclusion. The results from these studies suggest cautious use of records of growth stored in otoliths to make inferences about the attainment of competence.

Invertebrate larvae often have very specific cue requirements to induce metamorphosis and settlement. Thus in the laboratory, sequential preference experiments have enabled researchers to determine when larvae of a wide range of taxa are first competent to settle and how long they can subsequently postpone metamorphosis (Pechenik 1990, Davis 1994). The problem is that in culture, delays can only be demonstrated if we can ascertain when a larva becomes competent to metamorphose (Pechenik 1990). Larvae within a single batch of eggs vary in their genotype and developmental rates and thus may attain competence at different rates. No such experiments have been carried out with demersal fish species to date. The difficulties in rearing many fish species mean we have little understanding of the complex developmental changes that occur around and during metamorphosis (with the exception of perhaps flatfish).

Our inability to define competence has prohibited researchers from addressing the relative contributions of differing (pre-competent) developmental rates and delay in determining the PLD. The onset of competence in gastropods under controlled laboratory conditions is quite variable (Hadfield 1977). If McCormick's (1994) assertion that the goatfish Upeneus tragula is not capable of extensive delays is correct, then the timing of metamorphosis and settlement can be used as an approximation of competence. Given this assumption, laboratory studies on the species (McCormick \& Molony 1992, 1993, 1995) suggest that the onset of competence: (a) varies considerably among individuals that have experienced similar pelagic histories; (b) is 
strongly influenced by temperature and feeding history; and (c) may vary significantly among samples on relatively small spatial and temporal scales

\section{Cost of delays}

There may be a cost to delaying settlement. It is notable that in the present study, manini that delayed metamorphosis for $5 \mathrm{~d}$ and were then placed in aquarium suffered much higher levels of mortality than those fish that had not delayed, although this may be an experimental artifact. A number of researchers have found abnormal or poor juvenile survival after prolonged periods of delay in some lecithotrophic invertebrate larvae (e.g. Lucas et al. 1979, Morse et al. 1979). Pechenik (1990) thought the cost of delaying settlement was so important that he suggested the possible reduction in some components of juvenile fitness was a factor in determining the outcome of competitive interactions among sessile invertebrates. In reef fishes, growth rate is the only measure of fitness that has been examined for individuals with extended pelagic durations. To date, all studies have found no reduction in growth after settlement in fish with extended PLDs compared to earlier metamorphosing fish, despite most displaying major reductions in growth during their late larval life (Victor 1986, Cowen 1991, Sponaugle \& Cowen 1994, Masterson et al. 1997). This however, does not discount that those fish which undergo extended larval durations may be disadvantaged with respect to other attributes that may influence survival.

\section{Selective advantage of delay}

The finding of this and other studies (Chambers \& Leggett 1987, Thorrold \& Milicich 1990, McCormick 1994, Amara \& Lagardere 1995) of more variability in age than size at metamorphosis and settlement has been used to suggest that fish size is important in determining when an individual will settle. Cowen \& Sponaugle (1997) argue that the length of larval life may be determined by a tradeoff between: (a) remaining competent and enduring a slower growth rate, to maximise chances of settling under optimal conditions, and (b) settling rapidly to initiate higher growth rates as juveniles. Chambers \& Leggett (1992) ran simulations to show that the growth advantage gained through the early adoption of the juvenile habitat overrides any initial size disadvantage these juveniles may have from settling small. Although differences in size at settlement are found among locations and over time these are typically small in magnitude. Whatever the basis of the narrow size range at metamorphosis and settlement, it suggests that selection processes occurring in the plankton are more directional than those that influence which individuals survive to become reproductive. For example, it has been suggested that settling to the reef population at a large size for a species would be advantageous for escaping predators, competing for resources and mates, in what are characteristically size-dominated hierarchies (McCormick \& Kerrigan 1996, Sogard 1997, McCormick 1998). If this was of overwhelming importance, there would be a selective pressure for larvae to settle at larger and larger sizes. Obviously, there are tradeoffs, but presently we have more theoretical possibilities than data to address them.

Metamorphosis marks the irrevocable commitment of a fish to an ontogenetic niche shift from a dispersing larva to an almost sedentary and reproductive adult. Identifying the proximal causes of this transformation is fundamental to understanding how flexible growth and the ontogeny of complex life cycles have adapted to variable larval environments. This study has demonstrated conclusively that delays in metamorphosis are capable in 1 species of demersal fish. Experimental results stress that metamorphosis is not a single developmental process, but rather a complex of synchronised system changes. Some components of the transformation can be suspended once triggered (e.g. the overall morphological transformation), while others cannot (e.g. change in otolith growth trajectories, aspects of pigmentation). The capacity to manipulate the timing of metamorphosis may allow researchers to experimentally examine the physiological mechanisms underlying metamorphosis, whether there is a reliable indicator of competence, and the overall importance of delays to the dispersal of demersal fishes.

Acknowledgements. I am indebted to V. Dufour, B. Kerrigan, A. Zerbi, A. Lo-Yat, P. Roman, and members of the Service de la Mer et de l'Aquaculture in Raitatea, whose field assistance made the study possible. I particularly thank R. Partridge who spent many hours grinding otoliths and measuring fish. This paper was improved through comments from J. Leis, R. Cowen, S. Sponaugle and an anonymous reviewer. A. Baird kindly provided editorial comments. Research was conducted under JCU ethics approval no. A346. This research was funded through the Australian Research Council.

\section{LITERATURE CITED}

Amara R, Lagardere F (1995) Taille et age au debut de la metamorphose chez la sole (Solea solea (L.)) du golfe de Gascogne. ICES J Mar Sci 52:247-256

Campana SE, Neilson JD (1985) Microstructure of fish otoliths. Can J Fish Aquat Sci 42:1014-1032

Chambers RC, Leggett WC (1987) Size and age at metamorphosis in marine fishes: an analysis of laboratory-reared winter flounder (Pseudopleuronectes americanus) with a 
review of variation in other species. Can J Fish Aquat Sci 44:1936-1947

Chambers RC, Leggett WC (1992) Possible causes and consequences of variation in age and size at metamorphosis in flatfishes (Pleuronectiformes): an analysis at the individual, population and species levels. Neth J Sea Res 29:7-24

Cowen RK (1991) Variation in the planktonic larval duration of the temperate wrasse Semicossyphus pulcher. Mar Ecol Prog Ser 69:9-15

Cowen RK, Sponaugle S (1997) Relationship between early life history traits and recruitment among coral reef fishes. In: Chambers RC, Trippel EA (eds) Early life history and recruitment in fish populations. Chapman \& Hall, New York, p 423-449

Crisp DJ (1974) Factors influencing the settlement of invertebrate larvae. In: Grant PT. Mackie AM (eds) Chemoreception in marine organisms. Academic Press, New York, p $177-265$

Davis M (1994) Short-term competence in larvae of queen conch Strombus gigas - shifts in behavior, morphology and metamorphic response. Mar Ecol Prog Ser 104: $101-108$

Dufour V, Riclet E, Lo-Yat A (1996) Colonization of reef fishes at Moorea Island, French Polynesia: temporal and spatial variation of the larval flux. Mar Freshw Res 47:413-422

Emlet RB (1986) Larval production, dispersal, and growth in a fjord: a case study on larvae of the sand dollar Dendraster excentricus. PSZN I: Mar Ecol 31:245-254

Evans BI, Fernald RD (1990) Metamorphosis and fish vision. J Neurobiol 21:1037-1052

Fenaux L, Pedrotti ML (1988) Metamorphosis of echinoid larvae in midwater. Mar Ecol Prog Ser 9:93-107

Fowler AJ, Short DA (1996) Temporal variation in the early life-history characteristics of the King George whiting (Sillaginodes punctata) from analysis of otolith microstructure. Mar Freshw Res 47:809-818

Hadfield MG (1977) Chemical interactions in larval settling of a marine gastropod. In: Faulkner DJ, Fenical WH (eds) Marine natural products chemistry. Plenum Press, New York, p 403-413

Harvey AW (1996) Delayed metamorphosis in Florida hermit crabs: multiple cues and constraints (Crustacea: Decapoda: Paguridae and Diogenidae). Mar Ecol Prog Ser 141. $27-36$

Holmes JA, Beamish FWH, Seelye JG, Sower SA, Youson JH (1994) Long-term influence of water temperature, photoperiod, and food deprivation on metamorphosis of sea lamprey, Petromyzon marinus. Can J Fish Aquat Sci 51. 2045-2051

Jackson GA, Strathmann RR (1981) Larval mortality from offshore mixing as a link between precompetent and competent periods of development. Am Nat 118:16-26

Jenkins GP, May HMA. (1994) Variation in settlement and larval duration of King George whiting, Sillaginodes punctata (Sillaginidae), in Swan Bay, Victoria, Australia. Bull Mar Sci 54:281-296

Keefe M. Able KW (1993) Patterns of metamorphosis in summer flounder, Paralichthys dentatus. J Fish Biol 42 $713-728$

Leis JM, Carson-Ewart BM (1997) In situ swimming speeds of the late pelagic larvae of some Indo-Pacific coral-reef fishes. Mar Ecol Prog Ser 159:165-174

Leis JM, Rennis DS (1983) The larvae of Indo-Pacific coral reef fishes. University of Hawaii Press, Honolulu

Lipcius RN, Olmi EJ, Van Montfrans J (1990) Planktonic availability, molt stage and settlement of blue crab postlarvae. Mar Ecol Prog Ser 58:235-242
Lucas MI, Walker G, Holland DL, Crisp DJ (1979) An energy budget for the free-swimming and metamorphosing larvae of Balanus balanoides (Crustacea: Cirripedia). Mar Biol 55:221-229

Markle DF, Harris PM, Toole CL (1992) Metamorphosis and an overview of early-life-history stages in Dover sole Microstomus pacificus. Fish Bull 90:285-301

Masterson CF, Danilowicz BS, Sale PF (1997) Yearly and inter-island variation in the recruitment dynamics of the bluehead wrasse (Thalassoma bifasciatum, Bloch). J Exp Mar Biol Ecol 214:149-166

McCormick MI (1993) Development and changes at settlement in the barbel structure of the reef fish, Upeneus tragula (Mullidae). Environ Biol Fish 37:269-282

McCormick MI (1994) Variability in age and size at settlement of the tropical goatfish Upeneus tragula (Mullidae) in the northern Great Barrier Reef lagoon. Mar Ecol Prog Ser 103:1-15

McCormick MI (1998) Behaviorally induced maternal stress in a tropical fish influences progeny quality by a hormonal mechanism. Ecology 79:1873-1883

McCormick MI, Kerrigan BA (1996) Predation and its influence on the condition of a newly settled tropical demersal fish. Mar Freshw Res 47:557-562

McCormick MI, Molony BW (1992) Effects of feeding history on the growth characteristics of a reef fish at settlement. Mar Biol 114:165-173

McCormick MI, Molony BW (1993) Quality of the reef fish Upeneus tragula (Mullidae) at settlement: is size a good indicator of condition? Mar Ecol Prog Ser 98:45-54

McCormick MI, Molony BW (1995) Influence of water temperature during the larval stage on size, age and body condition of a tropical reef fish at settlement. Mar Ecol Prog Ser 118:59-68

McCormick MI, Shand J (1993) Metamorphosis of the visual and barbel sensory systems at settlement in the reef fish Upeneus tragula (Family Mullidae). Proc 7 th Int Coral Reef Symp 1:616-623

Modin J, Fagerholm B, Gunnarsson B, Pihl L (1996) Changes in otolith microstructure at metamorphosis of plaice, Pleuronectes platessa L. ICES J Mar Sci 53:745-748

Morse DE, Hooker N, Duncan H, Jensen L (1979) Gammaaminobutyric acid, a neurotransmitter, induces planktonic abalone to settle and begin metamorphosis. Science 204 $407-410$

Norris KS (1963) The functions of temperature in the ecology of the percoid fish Girella nignicans (Ayres). Ecol Monogr $33: 23-62$

Pechenik JA (1990) Delayed metamorphosis by larvae of benthic marine invertebrates: does it occur? is there a price to pay? Ophelia 32:63-94

Pechenik JA, Rittsch of D, Schmidt AR (1993) Influence of delayed metamorphosis on survival and growth of juvenile barnacles Balanus amphitrite. Mar Biol 115:287-294

Pitcher CR (1988) Validation of a technique for reconstructing daily patterns in the recruitment of coral reef damselfish. Coral Reefs 7:105-111

Planes S (1993) Genetic differentiation in relation to restricted larval dispersal of the convict surgeonfish Acanthurus triostegus in French Polynesia. Mar Ecol Prog Ser 98: $237-247$

Randall JE (1961) A contribution to the biology of the convict surgeonfish of the Hawaian islands, Acanthurus sandvicensis. Pac Sci 15:215-272

Richmond RH (1985) Reversible metamorphosis in coral planula larvae. Mar Ecol Prog Ser 22:181-185

Sancho G, Ma D, Lobel PS (1997) Behavioral observations of 
an upcurrent reef colonization event by larval surgeonfish Ctenochaetus strigosus (Acanthuridae). Mar Ecol Prog Ser 153:311-315

SAS Institute Inc (1987) SAS statistics guide, version 6 edition. SAS Institute Inc, Cary, NC

Shand J (1993) Changes in the spectral absorption of cone visual pigments during the settlement of the goatfish Upeneus tragula: the loss of red sensitivity as a benthic existence begins. J Comp Physiol 173:115-121

Shand J (1994) Changes in retinal structure during development and settlement of the goatfish Upeneus tragula. Brain Behav Evol 43:51-60

Shand J (1997) Ontogenetic changes in retinal structure and visual acuity: a comparative study of coral-reef teleosts with differing post-settlement lifestyles. Environ Biol Fish 49:307-322

Sogard SM (1997) Size-selective mortality in the juvenile stage of teleost fishes: a review. Bull Mar Sci 60:1129-1157

Sponaugle S, Cowen RK (1994) Larval durations and recruitment patterns of two Caribbean gobies (Gobiidae): contrasting early life histories in demersal spawners. Mar Biol 120:133-143

Sponaugle S, Cowen RK (1996) Larval supply and patterns of recruitment for two Caribbean reef fishes, Stegastes partitus and Acanthurus bahianus. Mar Freshw Res 47 : $433-447$

Sponaugle S, Cowen RK (1997) Early life history traits and recruitment patterns of Caribbean wrasses (labridae). Ecol Monogr 67:177-202

Stobutzki IC, Bellwood DR (1997) Sustained swimming abilities of the late pelagic stages of coral reef fishes. Mar Ecol Prog Ser 149:35-41

Editorial responsibility: Otto Kinne (Editor), Oldendorf/Luhe, Germany
Stoner AW, Ray M, Glazer RA, McCarthy KJ (1996) Metamorphic responses to natural substrata in a gastropod larva: decisions related to postlarval growth and habitat preference. J Exp Mar Biol Ecol 205:229-243

Suthers IM, Frank KT, Campana SE (1989) Spatial comparison of recent growth in postlarval Atlantic cod (Gadus morhua) off southwestern Nova Scotia: inferior growth in a presumed nursery area. Can J Fish Aquat Sci 46: $113-124$

Thorrold SR, Milicich MJ (1990) Comparison of larval duration and pre- and post-settlement growth in two species of damselfish, Chromis atripectoralis and Pomacentrus coelestis (Pisces: Pomacentridae), from the Great Barrier Reef. Mar Biol 105:375-384

Victor BC (1982) Daily otolith increments and recruitment in two coral-reef wrasses, Thalassoma bifasciatum and Halichoeres bivittatus. Mar Biol 71:203-208

Victor BC (1983) Settlement and larval metamorphosis produce distinct marks on the otoliths of the slippery dick, Halichoeres bivittatus. In: Reaka ML (ed) The ecology of deep and shallow coral reefs. Symposia Series for Undersea Research, NOAA Undersea Research Program. NOAA, Washington, DC, p 47-51

Victor BC (1986) Delayed metamorphosis with reduced larval growth in a coral reef fish (Thalassoma bifasciatum). Can J Fish Aquat Sci 43:1208-1213

Wilson DT, McCormick MI (1997) Spatial and temporal validation of settlement marks in the otoliths of tropical reef fishes. Mar Ecol Prog Ser 153:259-271

Wilson DT, McCormick MI (1999) Microstructure of settlement marks in the otoliths of tropical reef fish. Mar Biol (in press)

Submitted: April 7, 1998; Accepted: September 8, 1998 Proofs received from author(s): December 28, 1998 